DOI: $\underline{10.20472 / T E .2019 .7 .1 .006}$

\title{
TRAINING FEMALE ENTREPRENEURS: A SELF-GOVERNED OR TUTOR-DRIVEN LEARNING PROCESS?
}

\author{
ULIANA PROSKUNINA, JULIANE MOEHRING, KAETHE SCHNEIDER, \\ MONIKA STORCH
}

\begin{abstract}
:
The key features of female entrepreneurs' learning and its outcomes within the four dimensions of Kirkpatrick model are well documented. At the same time, each training program provides a unique instructional and social framework to be empirically explored. The current paper contributes to the evaluation of the Women Entrepreneurs: The Education and Training for Success Programme, which is a four-year project within the Horizon 2020 European Union initiative. We apply GLS Fixed-Effects and Logistic Regression models for a merged student-tutor log dataset to examine the interaction between participants' learning and instructors' direct facilitation levels. Our analysis shows that despite a low share of student-tutor interactions within the course activity, they are the only significant predictor of learners' engagement with the course content $(p<0.001)$ and dropout probability $(p<0.05)$. This implies that the exclusive application of the constructivist perspective for business education should be revisited, in particular with regard to the female firm owners.
\end{abstract}

\section{Keywords:}

Online learning behavior, instructional conditions, student-tutor interaction, contribution and observation, female entrepreneurs training

JEL Classification: A29

\section{Authors:}

ULIANA PROSKUNINA, Friedrich-Schiller-University Jena, Germany, Email:

uliana.proskunina@uni-jena.de

JULIANE MOEHRING, Friedrich-Schiller-University Jena, Germany, Email:

Juliane.Moehring@uni-jena.de

KAETHE SCHNEIDER, Friedrich-Schiller-University Jena, Germany, Email: k.schneider@uni-jena.de MONIKA STORCH, Friedrich-Schiller-University Jena, Germany, Email: Monika.Storch@uni-jena.de

\section{Citation:}

ULIANA PROSKUNINA, JULIANE MOEHRING, KAETHE SCHNEIDER, MONIKA STORCH (2019). Training female entrepreneurs: a self-governed or tutor-driven learning process? . International Journal of Teaching and Education, Vol. VII(1), pp. 73-91., 10.20472/TE.2019.7.1.006

Acknowledgements:

This project has received funding from the European Union's Horizon 2020 research and innovation 
programme under grant agreement No 645441. The authors would like to thank the European Commission for funding this research and innovation project. 


\section{Introduction}

Similar to other types of interventions, business training is traditionally associated with positive outcomes on both individual and organizational levels. Those among others include improved business knowledge and confidence, advanced entrepreneurial practices and performance, increased investment level and overall business formalization (Patel, 2014). Nevertheless, these expectations are not straightforward transferred to the training of female entrepreneurs due to the range of baseline constraints in venture managing and financing, social networks and cognitive traits (Maxfield, 2007, Betters-Reed et al., 2007). Therefore, literature on entrepreneurship education agrees on the necessity of a multidimensional multidisciplinary approach towards training of female firm owners, as well as its evaluation. Its fulfilment has become one of the major deliverables for the Women Entrepreneurs research, innovation and staff exchange project in the Horizon 2020 framework of the European Union.

Core of this project is a Moodle-based training program which has been developed to enhance the capacities of early stage women entrepreneurs and increase the success of their overall entrepreneurial performance. The current paper presents the first step in its evaluation process.

The four-level Kirkpatrick model (Kirkpatrick and Kirkpatrick, 2006) has been selected as a baseline theoretical framework. In its general terms, it implies estimation of training outcomes in the Reaction, Learning, Behavior and Results dimensions. The model implicitly assumes the hierarchy in the impact of each level to the subordinate one, but empirical application of the instrument provides evidences for the variety of interrelationship between them (Grohmann and Kauffeld, 2013). There is also no consensus upon the placement of levels within the timeline of short- and long-term training effects. The goals and needs of the evaluation drive the methodological decisions and place the focus on the selected dimensions. In the primary definition of model's creators (Kirkpatrick and Kirkpatrick, 2006), Reaction includes participants' feedback and suggestions, evaluation of trainers and standards of performance. Those directly impact the Learning dimension which constitutes the changes in attitudes, increase of knowledge and/or skills, which are the vital condition for Behavioral changes. Those reflect the extent of content application and its organizational usability. Results are the closest equivalent to the Return-On-the-Investment approach, delivering evidences for an actual positive impact of training on the organization. Although each higher rank level of Kirkpatrick model extends the understanding of learning outcomes, it is also connected to an increased number of methodological constraints.

Although quantifying training effects is of a major interest for cost bearers, it meets numerous critic points in the evaluation theory in general and in its application for training female firm owners in particular. For any kind of business, organizational changes take longer to implement; therefore, it is improbable to observe them immediately in a limited time perspective (McKenzie and Woodruff, 2013, Patel, 2014). Their implementation is additionally shaped by the variety of economic, politic and social environment factors (Kirkpatrick and Kirkpatrick, 2006) and is the most effective when combined with other types of interventions, mainly access to finance (Patel, 2014). Self-selectivity of training participants is a further obstacle for observing immediate training revenues, as firms of those who are interested in further education are often already wellmanaged (Karlan and Valdivia, 2011, Drexler et al., 2014, McKenzie and Woodruff, 2013). 
Betters-Reed and colleagues (Betters-Reed et al., 2007) argue for the complete unsuitability of quantitative indexes for measuring training outcomes for female entrepreneurs due to their embeddedness in high growth, high profit, large businesses. Therefore, an adapted solution for each program's evaluation is needed.

The integrated formative evaluation of a training program is reasonable to start from understanding the participants' learning processes (Ben-Zadok et al., 2009), analyzing the learning environment and practices (Mazza et al., 2012) that predict the achievement of the training outcomes. These goals are best fulfilled by employing learning analytics that point to the combination of the didactical perspective and the Reaction level of the Kirkpatrick model, which contains the primary information about training effectiveness. At the same time, the reflection of self-regulation, self-efficacy and autonomy in students' online behavior (Ben-Zadok et al., 2009), links the outlined approach to the Learning dimension. In terms of the research design, monitoring courses with log data has an advantage of ensuring more valid, reliable and objective performance measurements in comparison to surveys (Black et al., 2008), which gains special importance with regard to the target group.

The following research question guides our analysis. How is the learning engagement of the participants of the Women Entrepreneurs training program influenced by its instructional conditions? In addition to the core interest of evaluating the project on an empirical basis, we deliver relevant insights for the business education literature approaching the learning processes in the target group. The article proceeds as follows: the next section extends the theoretical and conceptual frameworks in terms of the selected approach. Then, we introduce the data selection within the project background and respective analytical procedure. The discussion of the results and their implications constitute the final part of the article.

\section{Theoretical Framework}

The Input-Process-Output model (Klieme et al., 2007) broadens our baseline evaluation approach. The learning process, which is the subject of the current evaluation, is fundamentally shaped by the training input factors of three spheres: individual, work-related and training design. Trainee characteristics include personal ones like attitudes, interests, values, trainee's perception of tasks and constraints; performance-related characteristics of trainability as a degree to which trainees are able to learn and apply materials of the program (Noe and Schmitt, 1986), previous level of the expertise in the field (Kirkpatrick and Kirkpatrick, 2006), educational level (Chowdhury and Endres, 2005), past training experiences (Baldwin and Ford, 1988); work-related characteristics such as expectations upon job-related outcomes; degree of engagement with work and career (Noe and Schmitt, 1986). Individual-level input factors are broadly recognized as the most important ones for the learning process and transfer. Work environment characteristics stand for internal organizational learning and communication culture (Kirkpatrick and Kirkpatrick, 2006), overall importance of skills as the business binding constraint (McKenzie and Woodruff, 2013), nature of business opportunity and business model (Schaper and Casimir, 2007). Training design characteristics describe the incorporation of learning principles, sequencing, job relevance of the training material (Baldwin and Ford, 1988) and teaching delivery (Sulčič and Sulčič, 2007). Its baseline level incorporates instructors' e-literacy, communication skills, personal characteristics and subject matter expertise. Authors agree that the major part of the training input 
factors is established prior to its start and exhibits little dynamics throughout training duration, remaining an important determinant of its outcomes.

The basics of learning analytics imply using interaction as a crucial component of online education process, and, therefore, its primary data unit. It is a fundamental source of information upon mutual actions among tutors, students and learning contents (Agudo-Peregrina et al., 2014). The number of classifications is introduced for their systematization. Turning the participants themselves into a learning resource, online interaction promotes students-centered learning incorporating their control and input, facilitates active participation, variety of its forms and indepth discussions, more profoundly than face-to-face programs (Davies and Graff, 2005, Thorpe, 2002, Anderson, 2004). Nevertheless, a particular contribution of each type to the learning process remains an empirical exercise to explore.

Several paradigms deliver implications for the online learning processes of female firm owners. A constructivist perspective on business education implies a process-driven pedagogy with an open self-governed decentralized subjective learning process supporting autonomy, self-reliance and independent thinking as prerequisites of students' engagement (Löbler, 2006), while an instructional perspective is based on objectivism and centered around knowledge acquisition.

Thus, empirical research indicates gender differences in entrepreneurial learning. Namely, information sharing and collaborative resources, personal and business mutual relationships, emotional exposure gain greater importance for formal knowledge acquisition of female business owners (Schaper and Casimir, 2007, Kailer, 2007, Ekanem, 2015, Pittaway and Cope, 2007, Coyle and Ellinger, 2001). This implies the importance of community in online learning environments and instructor-student interactions as a vital component for its active cumulation (Black et al., 2008). The instructional design approach extends the latter assigning the crucial role in course assess, participation and reflection to the online guidance (Kakouris, 2009). Instructorstudent interactions are reported to promote effective learning and teaching by means of intellectual stimulation and exchange of ideas (Agudo-Peregrina et al., 2014), maintain participants' confidence of it (Lin, 2015) and be a central component for retention (Li, 2012, Chang, 2004). The introduction of the tutorial learning paradigm bridges a contructivist and instructional design perspectives, as enabling independent learning is defined as the main instructional function (Thorpe, 2002). With this, course materials remain central for learning itself, whereas tutors enable its facilitation. The instructional conditions of the course are the product of their pedagogical, managerial, social and technical roles (Sulčič and Sulčič, 2007). It is important to underline that their evaluation is embedded in their correspondence to the participants' expectations instead of predetermined absolute values of performance scores (Chang, 2004). Gaining an empirical insight into the tutoring delivery and its impact on participants' learning decisions contributes to resolving the confusion in the introduced theoretical debates.

The stated research question requires a program manager approach (Mazza et al., 2012) which, in opposite to a teacher's one, focuses on interaction-related issues instead of the content. Those among others include collaboration between course agents, usage of platform resources, teachers' facilitation and students' learning levels embedded in the nature of interactions instead of their semantic load (Mazza et al., 2012, Agudo-Peregrina et al., 2014). The current state of literature contains valid reasons to expect a low share of instructor-student interactions in the 
course learning activity, but their significant positive influence on the participants' engagement. It is tested with the following hypothesis.

- Hypothesis 1: Interactions with tutors take a low share in the course load and are gradually substituted by interactions with the course content (Agudo-Peregrina, Iglesias-Pradas et al. 2014).

- Hypothesis 2: Students' engagement in training is stimulated by its instructional conditions (Gašević et al., 2016, Sulčič and Sulčič, 2007).

- Hypothesis 3: Interactions with tutors are central for preventing drop-outs in the program (Li, 2012, Chang, 2004).

The next section describes the incorporation of the outlined patterns into the research design.

\section{Conceptual Framework and Measurement of Variables}

We follow the approach of Hernández García and colleagues (Hernández García et al., 2017) treating Moodle platform as a collaborative setting with the increased information flow and number of social interactions, therefore, it is reasonable to employ the combination of the Agentand Mode-based (Activity level) classifications of interactions for measuring the variables of interest. The first one implies the differentiation between those with a Student, Tutor, Content and System. Due to the peculiarities in the structure of the examined learning platform and its resources, the latter two have to be combined into one category, which is reasonable with regard to its combination with the Mode-based classification. Under the same considerations, we introduce Supervisor as an additional target of interactions to account for their specific functionality with regard to the tutors. Mode-based (Activity level) classification divides interactions into observations (passive) and contributions (active). As direct tutors' facilitation and students' learning levels constitute our research interest, it is reasonable to confine to the second notion only. These conceptual frameworks are suitable to cover the online behavior of both instructors and participants.

The theoretical constructs have been operationalized into the following variables. Active StudentStudent interactions stand for participants' initiative towards exchange, cooperation, social construction of activities and assignments (Hernández García et al., 2017). They gain special importance for the creation of community by learning entrepreneurs, which is characterized as disperse, asynchronous and diverse (Löbler, 2006). The social interaction component of students' communication applies to the active Tutor-Tutor interactions either. Active Student-Tutor or TutorStudent interactions represent the extent to which participants receive instructors' proximity in the course (Hernández García et al., 2017). Active interactions with the System and/or Content are defined by the authors as a facilitator or a limiting factor in the quality and quantity for other types of interactions. In the rest of the paper, we proceed with marking the event by its agents solely (Source-Target), as contributions remain the main subject of the current analysis.

Following broadly validated recommendations (Hernández García et al., 2017, Gašević et al., 2016, Davies and Graff, 2005, Estacio and Raga Jr, 2017), we operate with interactions' frequency instead of their duration. The argumentation behind is the absence of information in the latter upon the fact that the agent actually performed the activity within the registered time, which becomes especially problematic when the resources are available for download. This does not 
diminish accounting for all the three aspects of tutoring delivery (Sulčič and Sulčič, 2007): quantity, frequency and quality. The latter is incorporated by the Mode-based classification and still remains imperfect unless its semantics is accounted for. The logs' retrieval from Moodle platform enables the straightforward construction of the corresponding variables.

Potential differences between programs make learning process and its evaluation highly situated (Gašević et al., 2016), which means that the current procedure is not free from shortcomings. The critic rests on the assumption that independent learning implies users' different ways of system utilization, varied learning strategies and styles (Ben-Zadok et al., 2009), hence, the presented conceptual framework does not consider the aspects of passive, individualized, distant and selflearning (e.g. completing assignments without submission, learning from interactions of more active students, etc.). Low priority given to the online activities and varying level of e-literacy causes alternative ways of communication between agents, unlogged or incompletely logged actions (Hampel and Pleines, 2013). These large differences in individual engagement are not depicted by the methodological framework of learning analytics.

A large share of the upcoming interpretations is derived from the bench of studies upon entrepreneurial learning. On the conceptual level, a narrow understanding of a formal knowledge acquisition is differentiated from a much more complex continuous experiential lifetime process of generating the necessary information for being effective in venture management (Politis, 2005), which is an integral part of entrepreneurial practices (Carwile, 2009, Abrar, 2004). The characteristics of the latter are fundamentally reflected in the examined learning behavior, turning each participants' interaction into a learning opportunity (Chupp, 2010, Carwile, 2009). Networking and practical tasks place the examined program design beyond rational knowledge acquisition making both learning aspects uneasy to separate. Therefore, their incorporation is necessary of its comprehensive understanding, whereas differentiation exceeds the goals of the current evaluation.

\section{Program Background and Research Data}

As the paper is aimed as an empirical project evaluation, we shortly introduce the structure and institutional framework of the Women Entrepreneurs: The Education and Training for Success Programme and its target group who constitute the research sample. Those are early-stage micro and small business women entrepreneurs from the service sector in Germany and Ireland. No other eligibility criteria have been established for participation.

Program content and design are aimed to meet individual learning objectives and based on the research upon the gaps and needs of the target group in their professional development. A blended-learning format with an approximate workload of three hours per week and three face-toface meetings in each country has been chosen under these considerations. Following courses, divided into modules and supported by Networking and Reflection unit, were offered to the participants: Understanding your company, Increasing requests for services, Knowing and managing technological changes, Customer management, Dealing with an increased competition. After their choice based on the assessment of individual entrepreneurial competencies, the students' tasks include working on the topic-related readings, videos and self-check quizzes, performing online exercises and submitting assignments on scheduled dates. 
The subject of the current analysis is the program's second round taking place from February 2018 for four months after the program's validation and adaptation in its pilot version. The learning process has been maintained by the Chair of Adult Education at the Friedrich-SchillerUniversity Jena (Germany). The students with comparable backgrounds in course thematic fields have been employed as tutors, having received continuous supervision. As the notion of learning support implies (Agudo-Peregrina et al., 2014), their core activities included administrative tasks, engagement with the learning community, working with the content and providing individual feedback. Further information upon the project is available on its official homepage http://womenentrepreneurs.info.

The sample is constructed of all 6 tutors and 23 program participants who gave a special permission for tracking their online behavior, blinded to the hypothesis of the study.

Under the consideration of a limited number of cases, no further hierarchy in the data structure could have been established and a similar students' and tutors' behavior in all the program courses has been assumed. Participants' self-selection did not become a problem, as their engagement level is normally distributed. The tutors' sample consists of 1 female and 5 male undergraduate students of Economics, Business Administration and Education, Finance; at the age of 23 to 30 at the time of training. The participants fulfil the criteria of the target group. The age variation stands between 33 and 55. The branch and managerial experience are heterogenous either, ranging between 0 and 8 , and 1 and 25 years respectively. Their educational background is characterized by a disproportionally high share of people with university and/or high school degrees (up to a Doctoral one). As the majority of them are gained in other fields than training-specific, the statistical portrait of the sample does not constitute a bias for further analysis. While our empirical results are robust with regard to the similar population, we do advise caution when extrapolating them to entrepreneurs or people in general.

Data logs were retrieved through the direct queries to the Moodle platform. Students' and tutors' data have been merged in the way participants were randomly assigned to instructors by chairing supervisors and afterwards deidentified. Time stamps allow for the construction of a strongly balanced equally spaced panel and straightforward registration of drop-outs. In other words, we use participants as units of analysis with 18 observations per person (number of program weeks) and include corresponding tutors' activities as explanatory variables. Week has been chosen as a panel time variable to account for participants' availability within their work schedule, whereas program dynamics is controlled by month dummies. The discussed elements fulfill the evaluation criteria for an entrepreneurs' training program (Glaub and Frese, 2011) and with this constitute a solid basis for further empirical analysis.

\section{Methods of Analysis}

The research design has been constructed under a strict consideration of the theoretical background. Learning is a dynamic process (Thorpe, 2002), therefore, patterns of rate and trend for the target variables have to be incorporated (Andreß et al., 2013), which implies the necessity of the longitudinal data modelling. We aim to investigate the effects of variables derived from the trace data, so a correlational (non-experimental) design has been chosen (Gašević et al., 2016).

We make several adjustments in the analytical procedure for each of the target variables. The main body of findings is produced using GLS Fixed-Effects models. Their major advantage is the 
possibility to control for the unobserved heterogeneity and treat the outlined training input factors as the unobserved unit effect focusing on the impact of time-varying predictors (Allison, 2009, Wooldridge, 2012, Giesselmann and Windzio, 2013, Andreß et al., 2013). The logic of the method is less concerned with measuring their instant change but sustainable influence, which is reasonable with regard to the prevalence of highly asynchronous communication between platform users.

The assumption behind the current methodological solution is the exclusive dependence of the learning decisions on the program's instructional conditions, holding the internal ones stable. In order to advocate the latter as a possible methodological shortcoming, we apply the considerations of Wooldrigde (2012). He notes the minor variation of within-unit effect with regard to the training research. Its quantification is not required in terms of the research question. Constructing separate models for each type of interactions accounts for students' preferences towards different participation forms and learning styles (Estacio and Raga Jr, 2017) and multiple viewpoints in the behavior analysis (Dobashi, 2017).

For estimating the causality in the dropout probability, a Multiple Logistic Regression model is employed to assess the predictive cumulative power of each type of interactions on the basis of their total number (Iglesias-Pradas et al., 2015). The application of both methods and interpretation of findings follow in the main body of the article.

\section{Findings and Discussion}

Before discussing the stimulus for students' contributions to the program learning activity, it is reasonable to gain an understanding upon their absolute shares and dynamics within each of the defined interaction types. This shall provide an empirical basis for testing the first hypothesis. Table 1 below delivers the corresponding figures.

Table 1. Structure of Students' Learning Behavior in the Training Program (Agent- and Mode-based Classifications): Valid Percentages

\begin{tabular}{|c|c|c|c|c|c|c|c|c|}
\hline \multirow[t]{3}{*}{ Month } & \multicolumn{8}{|c|}{ Type of interaction } \\
\hline & \multicolumn{2}{|c|}{ Student-Content/System } & \multicolumn{2}{|c|}{ Student-Student } & \multicolumn{2}{|c|}{ Student-Tutor } & \multicolumn{2}{|c|}{ Student-Supervisor } \\
\hline & \multirow{2}{*}{\multicolumn{2}{|c|}{$\begin{array}{c}\text { Contribution } \\
0.69\end{array}$}} & Contribution & Observation & Contribution & Observation & Contr. & Observ. \\
\hline \multirow{2}{*}{ February } & & & \multicolumn{2}{|c|}{0.26} & \multicolumn{2}{|c|}{0.05} & \multicolumn{2}{|c|}{$<0.01$} \\
\hline & 0.27 & 0.73 & 0.39 & 0.61 & 0.26 & 0.74 & 0.25 & 0.75 \\
\hline March & & & 0. & & 0. & & & .01 \\
\hline Anri & 0.25 & 0.75 & 0.52 & 0.48 & 0.21 & 0.79 & 0.00 & $01^{1.00}$ \\
\hline & 0.26 & 0.74 & 0.24 & 0.76 & 0.13 & 0.87 & 0.33 & 0.67 \\
\hline May & 0.33 & 0.67 & 0.29 & 0.71 & 0.17 & 0.83 & & 00 \\
\hline
\end{tabular}

Source: Moodle log data Women Entrepreneurs: The Education and Training for Success Programme, own calculations

The examined training program does not constitute an exception with regard to a widespread tendency of an online education towards a large gap between the number of observations and contributions (Hampel and Pleines, 2013, Iglesias-Pradas et al., 2015). The introduced importance of networking for entrepreneurial learning stands for the most symmetry at the beginning of peer communication in comparison to other fields and phases of online behavior. In consistence with the theoretical predictions, interactions with tutors take a second lowest share in the students' learning spectrum, which makes it highly individualized. Besides, they are increasingly asymmetric, which exhibits the superiority of tutors' facilitation level in comparison to 
participants' reciprocal initiative. Nevertheless, their share remains highly stable throughout the course and its partial substitution by the content takes place only in the last month of the program. The rates and dynamics of Content and/or System contributions prove the applicability of the constructivist perspective to interpret the centrality of platform materials for distant learning. Table 2 shows the respective computations for the tutors.

Table 2. Structure of Tutors' Teaching Behavior in the Training Program (Agent- and Modebased Classifications): Valid Percentages

\begin{tabular}{|c|c|c|c|c|c|c|c|c|}
\hline \multirow[t]{3}{*}{ Month } & \multicolumn{8}{|c|}{ Type of interaction } \\
\hline & \multicolumn{2}{|c|}{ Student-Content/System } & \multicolumn{2}{|c|}{ Student-Student } & \multicolumn{2}{|c|}{ Student-Tutor } & \multicolumn{2}{|c|}{ Student-Superviso } \\
\hline & Contribution & Observation & Contribution & Observation & Contribution & Observation & Contr. & Observ. \\
\hline \multirow[t]{2}{*}{ February } & \multicolumn{2}{|c|}{0.69} & \multicolumn{2}{|c|}{0.10} & \multicolumn{2}{|c|}{0.19} & \multicolumn{2}{|c|}{0.02} \\
\hline & 0.18 & 0.82 & 0.07 & 0.93 & 0.33 & 0.67 & 0.26 & 0.74 \\
\hline March & \multicolumn{2}{|c|}{0.70} & \multicolumn{2}{|c|}{0.09} & \multicolumn{2}{|c|}{0.19} & \multicolumn{2}{|c|}{0.02} \\
\hline \multirow{2}{*}{ April } & \multicolumn{2}{|c|}{0.67} & \multicolumn{2}{|c|}{0.09} & \multicolumn{2}{|c|}{0.23} & \multicolumn{2}{|c|}{0.01} \\
\hline & 0.18 & 0.82 & 0.06 & 0.94 & 0.23 & 0.77 & 0.16 & 0.84 \\
\hline \multirow[t]{2}{*}{ May } & \multirow{2}{*}{\multicolumn{2}{|c|}{0.68}} & \multirow{2}{*}{\multicolumn{2}{|c|}{0.08}} & \multirow{2}{*}{\multicolumn{2}{|c|}{0.23}} & \multirow{2}{*}{\multicolumn{2}{|c|}{0.01}} \\
\hline & & & & 0.93 & & 0.89 & & 0.93 \\
\hline
\end{tabular}

Source: Moodle log data Women Entrepreneurs: The Education and Training for Success Programme, own calculations

The discussed aspects of users' behavior in collaborative learning settings are also valid for the tutors' teaching behavior. Its differentiating features are lower sensitivity towards the overall program dynamics and their functional specificity aimed to students' facilitation. The latter, in addition to the discussed tendencies, is reflected in its increase in the second half of the program to prevent a typical participants' engagement reduction at this point (Pham et al., 2014). The represented aspects of the tutors' commitment prove the favorability of the instructional conditions for successful training completion accounted for the needs and preferences of the target group. We regard Hypothesis 1 as confirmed and proceed with the body of findings upon different aspects of students' learning behavior.

In terms of the constructivist perspective, students' contributions to the course content are regarded as the most fundamental elements (Hernández García et al., 2017) and products of the learning process (Gašević et al., 2016). Despite the assumption of a decreasing role of a contentdriven pedagogy in entrepreneurial training (Löbler, 2006), the major share of learning activities in the Women Entrepreneurs training program takes place in this field. It exhibits clearly the preference of female business owners for the "routinized" (Ekanem, 2015) and constant (Carwile, 2009) learning in opposite to their male comparts. From the students' side, the activities of this type include submitting assignments, taking quizzes, information sharing in forums and collective database, etc. The examples of tutors' activities are posting announcements, news, guidance, material update, presentation, clarification and others. Table 3 presents the causal dialectic between both. 
Table 3. Student-Content Contributions and Instructional Conditions: GLS Fixed-Effects Model

\begin{tabular}{|c|c|}
\hline & Coefficient (Standard Error) \\
\hline Constant & $1.00(0.83)$ \\
\hline Tutor-Content/System & $0.03^{*}(0.01)$ \\
\hline Tutor-Tutor & $-0.18(0.18)$ \\
\hline Tutor-Student & $0.10^{\star \star *}(0.03)$ \\
\hline Tutor-Supervisor & $0.15(0.14)$ \\
\hline Month. Baseline: February & \\
\hline March & $-0.89(0.74)$ \\
\hline April & $-1.28(0.85)$ \\
\hline May & $-0.40(0.88)$ \\
\hline $\mathrm{R}^{2}$ (within) & 0.13 \\
\hline sigma u & 2.27 \\
\hline sigma e & 4.66 \\
\hline rho & 0.19 \\
\hline
\end{tabular}

Note: ${ }^{* * *} p \leq 0.001,{ }^{* *} p \leq 0.01,{ }^{*} p \leq 0.05$

Source: Moodle log data Women Entrepreneurs: The Education and Training for Success Programme, own calculations

We find significant positive effects of tutors' facilitations through a direct interaction with a student and course contents on the students' engagement with the latter. For instance, each tutor's targeted communication initiative is associated with an estimated $10 \%$ increase in the expectation of students' Content/System contributions (Allison, 2009, Wooldridge, 2012, Giesselmann and Windzio, 2013, Andreß et al., 2013). The effect of the facilitation though the course materials aimed to all the participants is 0.07 weaker. Due to the absence of any significant time trends in the dependent variable, we conclude upon the persistence of participants' active engagement with the program content, which is a sign for their good quality (Mazza and Milani, 2005). The variation of the outcome is explained to 0.13 with the current selection of predictors and to 0.19 attributed to the fixed effects. Hence, among its further determinants, both personalized and common tutors' facilitation initiatives improve the way participants make use of the platform and its resources.

Previous studies provide numerous evidences for the importance of peer interactions for the online education and entrepreneurial training. At the same time, they are often the most problematic to achieve due to the major time constraints from both sides (Agudo-Peregrina et al., 2014). Within the examined program, they have been carefully fostered though Moodle collaborative tools (forums, blogs, chats), established pedagogical techniques (small working groups, learning dyads), collective database (created by continuous contributions to the participants' and sources' directories), face-to-face meetings and informal socializing (on a collaborative schedule basis). Remarkably, students' communication initiative remains independent on the tutors' one and decreases gradually within the program duration, which is shown in the Table 4 below. 
Table 4. Student-Student Contributions and Instructional Conditions: GLS Fixed-Effects Model

\begin{tabular}{|c|c|}
\hline & Coefficient (Standard Error) \\
\hline Constant & $1.41^{* *}(0.51)$ \\
\hline Tutor-Content/System & $0.00(0.01)$ \\
\hline Tutor-Tutor & $-0.02(0.11)$ \\
\hline Tutor-Student & $0.02(0.02)$ \\
\hline Tutor-Supervisor & $0.10(0.09)$ \\
\hline Month. Baseline: February & \\
\hline March & $-1.14^{\star \star}(0.45)$ \\
\hline April & $-1.60^{\star \star \star}(0.51)$ \\
\hline May & $-1.33^{\star \star}(0.54)$ \\
\hline $\mathrm{R}^{2}$ (within) & 0.08 \\
\hline sigma u & 0.64 \\
\hline sigma e & 2.83 \\
\hline rho & 0.05 \\
\hline
\end{tabular}

Note: ${ }^{* * *} p \leq 0.001,{ }^{* *} p \leq 0.01,{ }^{*} p \leq 0.05$

Source: Moodle log data Women Entrepreneurs: The Education and Training for Success Programme, own calculations

The findings are consistent with discussed characteristics of entrepreneurial community. As opposed to the content commitment, networking does not require moderator involvement and is completely participants-governed. Its nature is very close to the one of social learning (Abrar, 2004), being focused on the in-the-moment information needed, active exchange upon visions and experiences. This makes it emergent, participative, multi-layered, unstructured. The observed decrease in peer interactions reflect the reduced interest within the natural communication flow or strengthening the relationship by their transfer to alternative ways of communication (e.g. phone calls, emails, face-to-face contact). Initiative to engage with tutors extends our understanding of participants' learning by collaboration and interaction (Table 5).

Table 5. Student-Tutor Contributions and Instructional Conditions: GLS Fixed-Effects Model

\begin{tabular}{|c|c|}
\hline & Coefficient (Standard Error) \\
\hline Constant & $0.21^{\star \star \star}(0.07)$ \\
\hline Tutor-Content/System & $0.00(0.00)$ \\
\hline Tutor-Tutor & $-0.01(0.01)$ \\
\hline Tutor-Student & $0.01^{\star \star \star}(0.00)$ \\
\hline Tutor-Supervisor & $0.02(0.01)$ \\
\hline Month. Baseline: February & \\
\hline March & $-0.08(0.06)$ \\
\hline April & $-0.20^{\star \star \star}(0.07)$ \\
\hline May & $-0.17^{\star}(0.07)$ \\
\hline$\overline{\mathrm{R}^{2} \text { (within) }}$ & 0.14 \\
\hline sigma u & 0.17 \\
\hline sigma e & 0.38 \\
\hline rho & 0.17 \\
\hline
\end{tabular}


Similar to interactions between learners, engagement with tutors is highly self-governed. We find a significant positive association between communicative acts initiated by tutors with those of students, though of a low magnitude. It supports the "4P" assumption of tutors' effectivity, which includes positiveness, proactiveness, patience and persistence (Sulčič and Sulčič, 2007) to motivate students reciprocally. The decrease in the outcome variable in the second half of the program is less of a sign for the reduction in the engagement, but one of needs for a learning support in the course choice, preparatory diagnostics, assess to the resources, etc. (Thorpe, 2002). Due to the nature of the examined interaction, it is logical that the current model is the most successful in explaining different aspects of students' online behaviour through the course instructional conditions (Please use models estimates for reference).

As an interim conclusion at this point of analysis, we emphasize the importance of Tutor-Student interactions for students' learning attitudes and an effective learning environment, first and foremost, within the platform contents. The second hypothesis is confirmed. The enhanced comprehension, critical thinking and problem-solving skills; prior knowledge activation, establishment of new meaningful connections and their consolidation, multiplying view topics are the social interaction functions that explain didactically the current findings (Hurst et al., 2013). Tutors' regular feedback on submitted assignments stands for achieving learning through doing and reflection, which is vital for the target group (Chupp, 2010). Not only the information transfer, but a tutors' side perspective upon the participant's former experience and its transformation into knowledge, support functionally the established empirical connections. Despite the predominant role of reflection for entrepreneurial learning effectiveness (Löbler, 2006, Politis, 2005), peer interactions do not deliver similar evidences with this regard. Co-learning processes contribute to the reciprocal motivation to maintain this kind of interactions ( $\mathrm{Li}, 2012$, Nieuwenhuizen and Groenewald, 2008).

In contrast with this, participants' communicative behavior exhibits profound independence. The difference might origin from the distinction between the importance of autonomous self-directed learning for assessing informational capital and connected one for creating social capital (Thomas and Moisey, 2006). Its activity reduction and, despite that, a higher share in comparison to the one targeted for instructors indicate the need for alternative ways of encouragement (e.g. introducing mentorship and/or business consultants, more often face-to-face meetings, engaging participants with the projects, etc.).

It is widely documented that maintaining social interaction is important for both fundamental creation and persistent maintenance of the working environment. As attrition is one of its major products, we examine the latter in its dependence to the total number of interactions of different art (Table 6 below). The current model does not seek to establish a comprehensive analysis of the issue but underline the causal relationship between examined variables. 
Table 6. Predictors of Students‘ Drop-outs from the Program: Logistic Regression

\begin{tabular}{|l|c|c|c|c|}
\hline & \multirow{2}{*}{ B (Standard Error) } & \multicolumn{3}{|c|}{ 95\% Confidence Interval for Odds Ratio } \\
\cline { 3 - 5 } & $4.49^{*}$ & Lower & Odds Ratio & Upper \\
\hline Constant & -0.01 & 0.04 & 88.82 & 3860.20 \\
Student-Content / System & 0.00 & 0.87 & 0.99 & 1.02 \\
Student-Student & $-\mathbf{0 . 4 8 ^ { * }}$ & $\mathbf{0 . 3 9}$ & $\mathbf{0 . 6 2}$ & $\mathbf{0 . 9 9}$ \\
Student-Tutor & 2.53 & 0.39 & 12.49 & 395.62 \\
Student-Supervisor & 0.00 & & & \\
\hline Prob > chi2 & 0.49 & \multicolumn{4}{|l}{} \\
Pseudo R2 & \multicolumn{5}{|l}{} \\
\hline Note: ${ }^{* * *} \mathrm{p} \leq 0.001,{ }^{* *} \mathrm{p} \leq 0.01,{ }^{*} \mathrm{p} \leq 0.05$ &
\end{tabular}

Source: Moodle log data Women Entrepreneurs: The Education and Training for Success Programme, own calculations

When comparing the impact of different tasks on the retention in the Women Entrepreneurs training program, the ones with tutors are the only significant predictor of the outcome variable. Namely, each one additional initiative for the contact with an instructor decreases the predicted logarithmized chance of drop-out by 0.48 . Remarkably, that despite the widely discussed fundamental impact of the platform resources on learning, the one on the retention in the studied program is virtually zero.

Inconsistency of factors and situations affecting attrition, their uniqueness for single program designs (Street, 2010) and online populations of students (Park and Choi, 2009) contribute to the complexity and segmentation in the corresponding theoretical interpretations. Our findings are sound with the following authors. Institutional and social integration, that are the main tutors' functions, produce strong students' commitment and persistence (Tinto, 1993). Program dropouts can also be viewed within the estimated quality of the learning experience, which is highly dependent on the skills and commitment of online tutors (Thorpe, 2002). Among others, those include timely response time, sufficient supportiveness and comfortable relationships (Chang, 2004). Besides, tutoring intervention might be seen as a reduction of students' autonomy, which is proved to be negatively associated with dropout rates (Holder, 2007). The third hypothesis is considered confirmed and rounds up the findings of the current research.

\section{Conclusion}

The Women Entrepreneurs training program proves that sound instructional scaffolding, direct tutors' facilitation and leadership stimulate students' deeper approach to learning (Gašević et al., 2016). Interaction is regarded as the most effective mean in comparison to presentation and action as pedagogic strategies. Both persistence and retention aspects exhibit positive associations with them. Despite the fundamental difficulty to maintain the participation of the target group, the employed instructors manage to support and improve course performance and progression. Our findings give the basis to state that program tutors were being perceived as knowledgeable and trusted. The tutoring delivery is regarded as such that has met participants' expectations. The significant impact of Student-Tutor interactions on the dropout rate underlines instructors' special importance for alleviating students' isolation and helping them completing the program (Sulčič and Sulčič, 2007). We have valid reasons to expect further improvement in the 
skills and field expertise by the tutors as the result of the continuous contact to the participants (Li, 2012, Nieuwenhuizen and Groenewald, 2008). The implications for our findings are consistent with the ones of Agudo-Peregrina and colleagues (Agudo-Peregrina et al., 2014). Namely, promotion of users' interactions shall be prioritized in planning and developing programs for female business owners, though under a careful maintenance of the contents' quality. The latter have gained a positive assessment within the current evaluation.

Nevertheless, our findings do not diminish the central students' role in generating the fundamental benefits of the program. We do identify tendencies for engagement decrease in several spheres and provide theoretically proven implications for their reduction. Peer interactions remain the central issue with this regard. Their independence of the instructional conditions of the program and simultaneous need for additional stimulus requires a revisited approach towards its incorporation into the program design. Only the combination of a constructivist and instructional design approach gives us a full and satisfactory explanation of the examined learning processes.

The potential critics upon our findings are embedded in the presented limitation of their crossvalidation for different populations and necessity to expand the models with external environmental and individual factors affecting participation. The current research controls for them in a static manner without the effect quantification. The alternative explanations are related to the vision of the target group as non-traditional students. Dynamic external and internal factors are claimed to shape their engagement more profoundly than course characteristics (Bean and Metzner, 1985). Nevertheless, no consensus is still reached in the hierarchy of the impact (Park and Choi, 2009, Street, 2010). Besides, the chosen methodology of learning analytics is based on the narrow implication of constructivism. It brings potential limitations in the measurement of the variables, as well as in the theoretical interpretations. With this, an objectivist paradigm, which is another pillar of the instructional approach, is not accounted for. Despite these limitations, there can be little doubt upon the significance of the program instructional conditions for persistence and retention in the examined program and those of a similar type.

The directions of the future research originate from the placement of the current study in the variety of research methodologies for the Web log Analysis (Taksa et al., 2009). The patterns of reasons, purposes and quality of interactions should be covered for their comprehensive understanding. The study has limited capacities to verify essential didactical aspects like level of mastery achieved for specific skills (Mazza and Milani, 2005) or effectiveness of selective pedagogical techniques within the observed computer-mediated communication (Paulsen, 1995). Besides, we believe that the impact of specific program elements on participants personal and organizational development deserves a detailed investigation with regard to the fourth dimension of the Kirkpatrick model. We intend to follow up with these issues using a qualitative methodology.

Our research shows that the complexity of students' behavior does not compromise a widespread "individualized" vision of online training, in particular with regard to the business education. Its broad acceptance complies with broadly documented dropout rates across all the disciplines and, therefore, shall be further challenged by the continuous research of the issue. Does it mean a revival of a traditional student-teacher vision in adult education? We have provided valid and robust evidences of the guidance importance for engaging female entrepreneurs into effective 
learning. Remaining one of the possible implications of the phenomenon, they shall encourage studies for further verification and debates.

\section{References}

ABRAR, A. (2004). Entrepreneurial learning as experiential and social learning process: a case of female entrepreneurs in creative industry. Organization Learning, Knowledge and Capabilities Conference 2011.

AGUDO-PEREGRINA, Á. F., IGLESIAS-PRADAS, S., CONDE-GONZÁLEZ, M. Á. \& HERNÁNDEZGARCÍA, Á. (2014). Can we predict success from log data in VLEs? Classification of interactions for learning analytics and their relation with performance in VLE-supported F2F and online learning. Computers in Human Behavior, 31, 542-550. https://doi.org/10.1016/j.chb.2013.05.031

ALLISON, P. D. (2009). Fixed effects regression models, SAGE Publications. https://doi.org/10.4135/9781412993869

ANDERSON, T. (2004). Towards a theory of online learning. Theory and Practice of Online Learning, 2, 109-119.

ANDRES, H.-J., GOLSCH, K. \& SCHMIDT, A. W. (2013). Applied panel data analysis for economic and social surveys, Springer Science \& Business Media. https://doi.org/10.1007/978-3-642-32914-2

BALDWIN, T. T. \& FORD, J. K. (1988). Transfer of training: A review and directions for future research. Personnel Psychology, 41, 63-105. https://doi.org/10.1111/j.1744-6570.1988.tb00632.x

BEAN, J. P. \& METZNER, B. S. (1985). A conceptual model of nontraditional undergraduate student attrition. Review of Educational Research, 55, 485-540. https://doi.org/10.3102/00346543055004485

BEN-ZADOK, G., HERSHKOVITZ, A., MINTZ, E. \& NACHMIAS, R. (2009). Examining online learning processes based on log files analysis: A case study. 5th International Conference on Multimedia and ICT in Education 2009.

BETTERS-REED, B. L., MOORE, L. L. \& HUNT, L. M. (2007). A conceptual approach to better diagnosis and resolution of cross-cultural and gender challenges in entrepreneurial research. In A. Fayolle (ed.), Handbook of Research in Entrepreneurship Education: A General Perspective, Edward Elgar Publishing, Inc., 198-216. https://doi.org/10.4337/9781847205377.00020

BLACK, E. W., DAWSON, K. \& PRIEM, J. (2008). Data for free: Using LMS activity logs to measure community in online courses. The Internet and Higher Education, 11, 65-70. https://doi.org/10.1016/j.ineduc.2008.03.002

CARWILE, J. (2009). A case study of the self-directed learning of women entrepreneurs in the first four years of business ownership. Virginia Commonwealth University, Department of Educational Science.

CHANG, S. (2004). The roles of mentors in electronic learning environments. Aace Journal, 12, 331-342.

CHOWDHURY, S. \& ENDRES, M. (2005). Gender difference and the formation of entrepreneurial selfefficacy. United States Association of Small Business (USASBE) Annual Conference 2005.

CHUPP, B. K. (2010). An analysis of the learning processes of successful entrepreneurs. The University of Toledo, College of Graduate Studies.

COYLE, H. E. \& ELLINGER, A. D. (2001). Learning beliefs and strategies of female entrepreneurs: The importance of relational context in informal and incidental learning. Proceedings of the Academy of Human Resource Development.

DAVIES, J. \& GRAFF, M. (2005). Performance in e-learning: online participation and student grades. British Journal of Educational Technology, 36, 657-663. https://doi.org/10.1111/j.1467-8535.2005.00542.x

DOBASHI, K. (2017). Automatic data integration from Moodle course logs to pivot tables for time series cross section analysis. Procedia Computer Science, 112, 1835-1844. https://doi.org/10.1016/j.procs.2017.08.222 
DREXLER, A., FISCHER, G. \& SCHOAR, A. (2014). Keeping it simple: Financial literacy and rules of thumb. American Economic Journal: Applied Economics, 6, 1-31. https://doi.org/10.1257/app.6.2.1

EKANEM, I. (2015). Entrepreneurial learning: gender differences. International Journal of Entrepreneurial Behavior \& Research, 21, 557-577. https://doi.org/10.1108/IJEBR-08-2014-0146

ESTACIO, R. R. \& RAGA JR, R. C. (2017). Analyzing students online learning behavior in blended courses using Moodle. Asian Association of Open Universities Journal, 12, 52-68. https://doi.org/10.1108/AAOUJ-01-2017-0016

GAŠEVIĆ, D., DAWSON, S., ROGERS, T. \& GASEVIC, D. (2016). Learning analytics should not promote one size fits all: The effects of instructional conditions in predicting academic success. The Internet and Higher Education, 28, 68-84. https://doi.org/10.1016/j.iheduc.2015.10.002

GIESSELMANN, M. \& WINDZIO, M. (2013). Regressionsmodelle zur Analyse von Paneldaten, SpringerVerlag.

GLAUB, M. \& FRESE, M. (2011). A critical review of the effects of entrepreneurship training in developing countries. Enterprise Development and Microfinance, 22, 335-353. https://doi.org/10.3362/17551986.2011 .035

GROHMANN, A. \& KAUFFELD, S. (2013). Evaluating training programs: Development and correlates of the questionnaire for professional training evaluation. International Journal of Training and Development, 17, 135-155. https://doi.org/10.1111/ijtd.12005

HAMPEL, R. \& PLEINES, C. (2013). Fostering student interaction and engagement in a virtual learning environment: An investigation into activity design and implementation. Calico Journal, 30, 342-370. https://doi.org/10.11139/cj.30.3.342-370

HERNÁNDEZ GARCÍA, Á., ACQUILA NATALE, E. \& CHAPARRO PELAEZ, J. J. (2017). Current state of Learning Management Systems' log data-based learning analytics. 17th Biennial EARLI Conference for Research on Learning and Instruction.

HOLDER, B. (2007). An investigation of hope, academics, environment, and motivation as predictors of persistence in higher education online programs. The Internet and Higher Education, 10, 245-260. https://doi.org/10.1016/j.iheduc.2007.08.002

HURST, B., WALLACE, R. \& NIXON, S. B. (2013). The impact of social interaction on student learning. Reading Horizons, 52, 5.

IGLESIAS-PRADAS, S., RUIZ-DE-AZCÁRATE, C. \& AGUDO-PEREGRINA, Á. F. (2015). Assessing the suitability of student interactions from Moodle data logs as predictors of cross-curricular competencies. Computers in Human Behavior, 47, 81-89. https://doi.org/10.1016/j.chb.2014.09.065

KAILER, N. (2007). Evaluation of entrepreneurship education: planning problems, concepts and proposals for evaluation design. In A. Fayolle (ed.), Handbook of Research in Entrepreneurship Education: Contextual Perspectives, Edward Elgar Publishing, Inc.,221-243. https://doi.org/10.4337/9781847206985.00025

KAKOURIS, A. (2009). Online platforms for entrepreneurship education: An instructional design approach. 4th European Conference on Entrepreneurship and Innovation.

KARLAN, D. \& VALDIVIA, M. (2011). Teaching entrepreneurship: Impact of business training on microfinance clients and institutions. Review of Economics and Statistics, 93, 510-527. https://doi.org/10.1162/REST_a_00074

KIRKPATRICK, D. L. \& KIRKPATRICK, J. D. (2006). Evaluating training programs: the four levels, BerrettKoehler.

KLIEME, E., AVENARIUS, H., BAETHGE, M., DÖBERT, H., HETMEIER, H.-W., MEISTER-SCHEUFELEN, G., RAUSCHENBACH, T. \& WOLTER, A. (2007). Grundkonzeption der Bildungsberichterstattung für Deutschland. Bildungs-und Sozialberichterstattung, Springer. https://doi.org/10.1007/978-3-53190615-7_12 
LI, L. (2012). Student Misbehaviors and Teacher Techniques in Online Classrooms: Instrument Development and Validation. Ohio University, Department of Communication Studies

LIN, E. Z. F. L. C. H. (2015). The effect of teacher-student interactions on students' learning achievement in online tutoring environment. International Journal of Technical Research and Applications, 10, 19-22.

LÖBLER, H. (2006). Learning entrepreneurship from a constructivist perspective. Technology Analysis \& Strategic Management, 18, 19-38. https://doi.org/10.1080/09537320500520460

MAXFIEL, S. (2007). The entrepreneurship gender gap in global perspective: implications for entrepreneurship education and programming. In A. Fayolle (ed.), Handbook of Research in Entrepreneurship Education: Contextual Perspectives, Edward Elgar Publishing, Inc., 40-51.

MAZZA, R., BETTONI, M., FARÉ, M. \& MAZZOLA, L. (2012). Moclog-monitoring online courses with log data. 1st Moodle Research Conference.

MAZZA, R. \& MILANI, C. (2005). Exploring usage analysis in learning systems: Gaining insights from visualisations. Workshop on Usage Analysis in Learning Systems at 12th International Conference on Artificial Intelligence in Education.

MCKENZIE, D. \& WOODRUFF, C. (2013). What are we learning from business training and entrepreneurship evaluations around the developing world? The World Bank Research Observer, 29, 48-82. https://doi.org/10.1093/wbro//kt007

NIEUWENHUIZEN, C. \& GROENEWALD, D. (2008). Entrepreneurs' learning preferences: A guide for entrepreneurship education. Professional Accountant, 8, 128-144. https://doi.org/10.4102/ac.v8i1.76

NOE, R. A. \& SCHMITT, N. (1986). The influence of trainee attitudes on training effectiveness: Test of a model. Personnel Psychology, 39, 497-523. https://doi.org/10.1111/j.1744-6570.1986.tb00950.x

PARK, J.-H. \& CHOI, H. J. (2009). Factors influencing adult learners' decision to drop out or persist in online learning. Journal of Educational Technology \& Society, 12, 207-217.

PATEL, P. (2014). Effectiveness of entrepreneurship development interventions for women entrepreneurs: An ILO-WED Issue Brief. Geneva, Switzerland: Women's Entrepreneurship Development Programme, International Labour Organization.

PAULSEN, M. F. (1995). The online report on pedagogical techniques for computer-mediated communication. NKI Oslo.

PHAM, T., THALATHOTI, V. \& DAKICH, E. (2014). Frequency and pattern of learner-instructor interaction in an online English language learning environment in Vietnam. Australasian Journal of Educational Technology, 30, 686-698. https://doi.org/10.14742/ajet.608

PITTAWAY, L. \& COPE, J. (2007). Simulating entrepreneurial learning: Integrating experiential and collaborative approaches to learning. Management Learning, 38, 211-233. https://doi.org/10.1177/1350507607075776

POLITIS, D. (2005). The process of entrepreneurial learning: A conceptual framework. Entrepreneurship Theory and Practice, 29, 399-424. https://doi.org/10.1111/j.1540-6520.2005.00091.x

SCHAPER, M. T. \& CASIMIR, G. (2007). The impact of tertiary education courses on entrepreneurial goals and intentions. In A. Fayolle (ed.), Handbook of Research in Entrepreneurship Education: Contextual Perspectives, Edward Elgar Publishing, Inc., 120-129. https://doi.org/10.4337/9781847206985.00016

STREET, H. (2010). Factors influencing a learner's decision to drop-out or persist in higher education distance learning. Online Journal of Distance Learning Administration, 13, 4.

SULČIČ, V. \& SULČIČ, A. (2007). Can online tutors improve the quality of e-learning. Issues in Informing Science and Information Technology, 4, 201-210. https://doi.org/10.28945/943

TAKSA, I., SPINK, A. \& JANSEN, B. J. (2009). Web log analysis: Diversity of research methodologies. In B. J. Jansen, A. Spink \& I. Taksa (ed.), Handbook of Research on Web Log Analysis, IGI Global, 506522. https://doi.org/10.4018/978-1-59904-974-8.ch025 
THOMAS, P. \& MOISEY, S. D. (2006). Women Entrepreneurs: Informal Learning and the Internet. Athabasca University, Centre for Distance Education. https://doi.org/10.1080/08276331.2006.10593366

THORPE, M. (2002). Rethinking learner support: The challenge of collaborative online learning. Open Learning, 17, 105-119. https://doi.org/10.1080/02680510220146887a

TINTO, V. (1993). Leaving college rethinking the causes and cures of student attrition, University of Chicago Press.

WOOLDRIDGE, J. (2012). Introductory econometrics: A modern approach, South-Western Cengage Learning. 